\title{
Visuomotor adaptive improvement and aftereffects are impaired differentially following cerebellar lesions in SCA and PICA territory
}

\author{
Susen Werner • Otmar Bock • Elke R. Gizewski • \\ Beate Schoch · Dagmar Timmann
}

Received: 25 May 2009/Accepted: 7 October 2009/Published online: 3 November 2009

(c) The Author(s) 2009. This article is published with open access at Springerlink.com

\begin{abstract}
The aim of the present study was to elucidate the contribution of the superior and posterior inferior cerebellum to adaptive improvement and aftereffects in a visuomotor adaptation task. Nine patients with ischemic lesions within the territory of the posterior inferior cerebellar artery (PICA), six patients with ischemic lesions within the territory of the superior cerebellar artery (SCA) and 17 age-matched controls participated. All subjects performed center-out reaching movements under $60^{\circ}$ rotation of visual feedback. For the assessment of aftereffects, we tested retention of adaptation and de-adaptation under $0^{\circ}$ visual rotation. From this data we also quantified five measures of motor performance. Cerebellar lesionsymptom mapping was performed using magnetic resonance imaging subtraction analysis. Adaptive improvement during $60^{\circ}$ rotation was significantly degraded in PICA patients and even more in SCA patients. Subtraction analysis revealed that posterior (Crus I) as well as anterior cerebellar regions (lobule V) showed a common overlap
\end{abstract}

\author{
S. Werner $(\bowtie) \cdot$ O. Bock \\ Institute of Physiology and Anatomy, \\ German Sport University, 50927 Cologne, Germany \\ e-mail: Werner@dshs-koeln.de

\section{E. R. Gizewski} \\ Department of Diagnostic and Interventional Radiology \\ and Neuroradiology, University of Duisburg-Essen, \\ Essen, Germany \\ B. Schoch \\ Department of Neurosurgery, \\ University of Duisburg-Essen, Essen, Germany \\ D. Timmann \\ Department of Neurology, \\ University of Duisburg-Essen, Essen, Germany
}

related to deficits in adaptive improvement. However, for aftereffect measures as well as for motor performance variables only SCA patients, but not PICA patients showed significant differences to control subjects. Subtraction analysis showed that affection of lobules V and VI were more common in patients with impaired retention and deadaptation, respectively. Data shows that areas both within the superior and posterior inferior cerebellum are involved in adaptive improvement. However, only the superior cerebellum including lobules V and VI appears to be important for aftereffects and therefore true adaptive ability.

Keywords Sensorimotor coordination - Cerebellum . Ataxia $\cdot$ Motor learning $\cdot$ Pointing $\cdot$ SCA $\cdot$ PICA

\section{Introduction}

It has been argued in the past that sensorimotor adaptation depends on the integrity of the cerebellum, since patients with cerebellar disease show impaired adaptation to force fields (Maschke et al. 2004; Smith and Shadmehr 2005) and visual distortions while walking (Morton and Bastian 2004), pointing (Gauthier et al. 1979; Synofzik et al. 2008; Tseng et al. 2007; Weiner et al. 1983; Werner et al. 2008), or performing ballistic elbow flexion and extension movements (Deuschl et al. 1996). Not only adaptive improvement, that is the reduction of errors during adaptation phase, but also aftereffects (Maschke et al. 2004; Morton and Bastian 2004; Smith and Shadmehr 2005; Synofzik et al. 2008; Tseng et al. 2007; Weiner et al. 1983; Werner et al. 2008) and generalisation (Morton and Bastian 2004) were found to be degraded. Aftereffect tests such as de-adaptation, retention or catch trials (that is single trials without perturbation during the adaptation phase) are 
Table 1 Basic characteristics of patients in the present study

\begin{tabular}{|c|c|c|c|c|c|c|c|c|c|}
\hline \multirow[t]{3}{*}{ Patient } & \multirow[t]{3}{*}{ Age } & \multirow[t]{3}{*}{ Sex } & \multirow[t]{3}{*}{ Cerebellar disorder } & \multirow[t]{3}{*}{ Duration of disease } & \multirow[t]{3}{*}{ Side } & \multirow[t]{3}{*}{ Volume } & \multicolumn{3}{|c|}{ Ataxia rating scale } \\
\hline & & & & & & & \multirow[t]{2}{*}{ Total } & \multicolumn{2}{|c|}{ Upper-limb } \\
\hline & & & & & & & & Right & Left \\
\hline $\mathrm{CZ}$ & 41 & $\mathrm{~F}$ & PICA & 19 & $\mathrm{~L}$ & 0.4 & 0 & 0 & 0 \\
\hline FL & 59 & M & PICA & 8 & $\mathrm{~L}$ & 1.7 & 0 & 0 & 0 \\
\hline GE & 59 & M & PICA & 13 & $\mathrm{R}$ & 9.9 & 0 & 0 & 0 \\
\hline MT & 42 & M & PICA & 20 & $\mathrm{R}$ & 22.8 & 0 & 0 & 0 \\
\hline RK & 46 & M & PICA & 19 & $\mathrm{~L}$ & 11.9 & 0 & 0 & 0 \\
\hline $\mathrm{SC}$ & 69 & M & PICA & 18 & $\mathrm{R}$ & 10.3 & 6 & 1 & 1 \\
\hline WS & 57 & M & PICA & 15 & $\mathrm{R}$ & 31.4 & 2 & 0 & 0 \\
\hline JM & 64 & M & PICA & 7 & $\mathrm{~L}$ & 22.7 & 1 & 0 & 0 \\
\hline KM & 65 & M & PICA & 16 & $\mathrm{~L}$ & 30.5 & 6 & 0 & 3 \\
\hline HG & 67 & $\mathrm{M}$ & SCA & 0 & $\mathrm{~L}$ & 2.6 & 4 & 1 & 2 \\
\hline JL & 18 & $\mathrm{~F}$ & SCA & 12 & $\mathrm{~L}$ & 1.0 & 0 & 0 & 0 \\
\hline KW & 75 & M & SCA & 46 & $\mathrm{~L}$ & 5.3 & 7 & 0 & 2 \\
\hline LR & 72 & M & SCA & 11 & $\mathrm{R}$ & 1.2 & 2 & 1 & 0 \\
\hline $\mathrm{LZ}$ & 69 & $\mathrm{~F}$ & SCA & 22 & $\mathrm{R}$ & 0.3 & 4 & 0 & 1 \\
\hline MM & 56 & M & SCA & 15 & $\mathrm{~L}$ & 1.1 & 2 & 0 & 0 \\
\hline
\end{tabular}

Age, sex (F-female; M-male), cerebellar disorder (PICA, infarct of posterior inferior cerebellar artery; SCA, infarct of superior cerebellar artery), duration of disease (time since lesion in months), side (R-right, L-left), volume of the lesion (in cubiccentimeters), and total as well as upper-limp ataxia scores from SARA (Scale for the assessment and rating of ataxia; Schmitz-Hubsch et al. 2006). Note that subscores of upperlimb ataxia of the right and left arm were summed up, and no means were taken as in the original publication
Seidler and Noll 2008; Seidler et al. 2006), whereas others found activation both in the superior and the posterior inferior cerebellum (lobules VIIB and VIII; Diedrichsen et al. 2005; Nezafat et al. 2001). It has to be noted, however, that not all studies carefully controlled for cerebellar activation related to motor performance such as hand acceleration or on-line motor corrections, which also have been shown to activate the superior (Diedrichsen et al. 2005; Grafton et al. 2008; Seidler et al. 2004), but also inferior parts of the cerebellum (lobule VIII; Diedrichsen et al. 2005).

The comparison of patients with ischemic stroke within the territory of the superior cerebellar artery (SCA) and the posterior inferior cerebellar artery (PICA) is a useful human cerebellar lesion condition to further elucidate the contribution of the superior and inferior cerebellum to sensorimotor adaptation. The SCA commonly supplies the anterior lobe (lobules I-V) and the more superior parts of the posterior lobe (lobules VI and Crus I), whereas the PICA commonly supplies the more inferior parts of the posterior lobe (lobules Crus II-X). Vascular territories, however, are variable and PICA strokes can involve Crus I (Timmann et al. 2009 for recent review).

As yet, two human vascular cerebellar lesion studies have assessed visuomotor adaptation. These studies have revealed contradictory results. One single-case study found a marked adaptation deficit following an SCA lesion (Pisella et al. 2005); however the other, well-cited study claimed that PICA lesions result in adaptation deficits but intact motor performance (Martin et al. 1996). To clarify this issue, we decided to compare motor performance and 
Table 2 Cerebellar lesion site

\begin{tabular}{|c|c|c|c|c|}
\hline \multirow[t]{2}{*}{ Patient } & \multirow[t]{2}{*}{ Vermis } & \multicolumn{2}{|l|}{ Hemisphere } & \multirow[t]{2}{*}{ Nuclei } \\
\hline & & Paravermal & Lateral & \\
\hline $\mathrm{CZ}$ & n.a. & n.a. & 1: CRI, CRII & n.a. \\
\hline FL & VIIAt, VIIB, VIIIA & 1: CRII, VIIB, VIIIA, VIIIB, IX & n.a. & n.a. \\
\hline GE & $\begin{array}{l}\text { CRII, VIIAt, VIIB, } \\
\text { VIIIB }\end{array}$ & r: CRI, CRII, VIIB, VIIIA, VIIIB & r: CRI, CRII, VIIB, VIIIA & $(\mathrm{r}: \mathrm{NI}) \mathrm{r}: \mathrm{ND}$ \\
\hline MT & n.a. & $\begin{array}{l}\text { r: CRI, CRII, VIIA, VIIB, VIIIA, } \\
\text { VIIIB, IX }\end{array}$ & r: CRI, CRII, VIIB, VIIIA, VIIIB & n.a. \\
\hline RK & $\begin{array}{l}\text { VIIAt, VIIB, VIIIA, } \\
\text { VIIIB, IX, X }\end{array}$ & $\begin{array}{l}\text { 1: (CRI), CRII, VIIA, VIIB, VIIIA, } \\
\text { VIIIB, IX }\end{array}$ & 1: CRI, CRII, VIIB, VIIIA, VIIIB & 1: ND p \\
\hline $\mathrm{SC}$ & $\begin{array}{l}\text { VIIAt, VIIB, VIIIA, } \\
\text { VIIIB, IX }\end{array}$ & r: CRII, VIIB, VIIIA, VIIIB, IX & r: CRII, VIIB, VIIIA, VIIIB & n.a. \\
\hline WS & n.a. & $\begin{array}{l}\text { r: CRI, CRII, VIIA, VIIB, VIIIA, } \\
\text { VIIIB, IX }\end{array}$ & $\begin{array}{l}\text { r: VI, CRI, CRII, VIIA, VIIB, } \\
\text { VIIIA, VIIIB, IX }\end{array}$ & $\mathrm{r}: \mathrm{ND} p$ \\
\hline $\mathrm{JM}$ & n.a. & 1: (CRI), CRII, VIIB, VIIIA, VIIIB & 1: CRI, CRII, VIIB, VIIIA, VIIIB & (1: ND) \\
\hline KM & $\begin{array}{l}\text { VIIAt, VIIB, VIIIA, } \\
\text { VIIIB, IX, X }\end{array}$ & $\begin{array}{l}\text { 1: CRI, CRII, VIIB, VIIIA, VIIIB, } \\
\text { IX }\end{array}$ & 1: CRI, CRII, VIIB, VIIIA, VIIIB & (1: ND) \\
\hline $\mathrm{HG}$ & n.a. & 1: IV, V, VI & 1: VI, CRI, CRII & n.a. \\
\hline JL & n.a. & 1: IV, V, VI & $(\mathrm{l}: \mathrm{VI})$ & (1: ND) \\
\hline KW & III, IV, V, VI & $1: \mathbf{V}, \mathbf{V I}$ & n.a. & (l: NI) \\
\hline LR & n.a. & r: V, VI & n.a. & (r: ND) \\
\hline $\mathrm{LZ}$ & n.a. & $\mathrm{r}:(\mathbf{V}), \mathbf{V I}$ & (r: VI, CRI) & n.a. \\
\hline MM & n.a. & 1: $\mathbf{V}, \mathbf{V I}$ & 1: VI & n.a. \\
\hline
\end{tabular}

Cerebellar lobules are named according to Schmahmann et al. (2000). $R$ right side, $l$ left side, $N I$ interposed nucleus, $N D$ dentate nucleus, $n . a$. not affected, $p$ posterior part of dentate, brackets indicate partial lesions. Common lesions sites in SCA patients are marked in bold letters

visuomotor adaptation in a larger sample of patients with either PICA or SCA territory involvement.

\section{Materials and methods}

Subjects

We acquired data from fifteen patients with unilateral focal cerebellar lesions (mean age $57.3 \pm 15.1$ years; 3 female, 12 male). Nine patients had ischemic infarction within the PICA territory. Mean age in this patient group was $55.8 \pm$ 10.3 years, mean time since lesion was 15.0 months, and their mean score on the Scale for the Assessment and Rating of Ataxia (Schmitz-Hubsch et al. 2006) was 1.7. Six patients presented with ischemic infarction within the SCA territory. Their mean age was $59.5 \pm 21.3$ years, mean time since lesion was 17.7 months, and their mean ataxia score was 3.2. Thus, the magnitude of ataxia was mild in both patient groups. A general survey of patients' clinical and lesion data is given in Table 1. The location and extent of cerebellar lesions was defined from magnetic resonance imaging (MRI) data sets, as summarized in Table 2. MRI revealed no extra-cerebellar lesions in any patient.

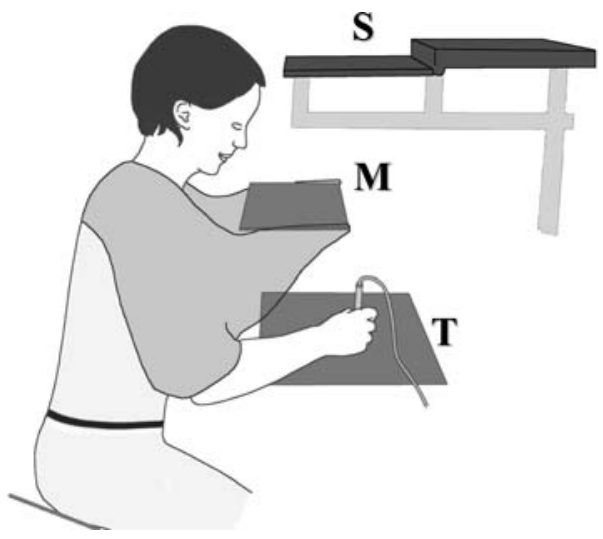

Fig. 1 Scheme of experimental apparatus with display screen $(S)$, mirror $(M)$, and digitizing tablet $(T)$

A group of 17 healthy, adult volunteers (mean age $54.6 \pm 8.6$ years; 8 females, 9 males) with no history of neurological disease served as controls. Their data have already been presented in our preceding study (Werner et al. 2008). All patients and controls were right-handed, and did not use any drugs affecting the nervous system. None of the subjects had prior experience in visuomotor research. The authors' local Ethics Committee had 
approved the procedure of the experiment, and all subjects gave written informed consent.

Visuomotor adaptation task

As in our previous study (Werner et al. 2008), subjects sat in front of a digitising tablet holding a pen as shown in Fig. 1. They watched a computer screen through a horizontally mounted mirror that projected the image of the screen onto the tablet. The mirror and surrounding shrouds prevented the sight of the arm. A central starting dot and one of eight possible target dots appeared alternately on the screen. The starting dot remained on for $0.3-0.5 \mathrm{~s}$, and was then replaced by one of the target dots, according to a random sequence. The targets were equally distributed on an imaginary circle of $10 \mathrm{~cm}$ radius about the centre, and each lit up for $2.0 \mathrm{~s}$. All subjects were instructed to move the pen as accurately and quickly as possible from the starting dot to the target and back. The position of the digitising pen was registered (resolution $0.3 \mathrm{~mm}, 60 \mathrm{~Hz}$ ), and displayed on the screen as a cursor to provide visual feedback about momentary hand position.

The experiment was subdivided into episodes of $30 \mathrm{~s}$ duration, separated by rest breaks of about $5 \mathrm{~s}$. Within one episode, 6-12 targets were presented. If not stated otherwise, subjects pointed with their dominant, right hand. All were familiarized with the experimental set-up by performing one episode under veridical visual feedback, i.e., pen and cursor position coincided. Data registration began with a baseline phase of four episodes, again under veridical feedback, with the left hand used during the first of those episodes. The subsequent adaptation phase consisted of 20 episodes, in which visual feedback was rotated by $-60^{\circ}$ about the starting dot. After a 1-day to 1 -week break $^{1}$ subjects returned and performed five episodes in a retention phase, once again under $-60^{\circ}$ rotated feedback. This was followed by two episodes of an intermanual transfer phase using the left hand, and one refresh episode using the right hand, again under rotated visual feedback. Finally came a de-adaptation phase of five episodes under veridical visual feedback. The whole experiment including instructions lasted about $20 \mathrm{~min}$ on the first, and about 10 min on the second day.

Even though all patients presented with unilateral lesions either in the right or left cerebellum, they all conducted the greatest part of the experiment with their dominant right hand. This is justified by the fact, that even for healthy subjects visuomotor adaptation with the right

\footnotetext{
1 The patients were also participating in a different study where mixed pause lengths were necessary. The results of our previous study show no effect of break length on retention, transfer and de-adaptation (Werner et al. 2008).
}

hand is faster, independent of the subjects' handedness (Chase and Seidler 2008). Since we still had the possibility to analyse the effect of lesion laterality (see below), we chose to keep the task as practicable as possible for the cerebellar patients.

Data analysis

Subjects' responses were quantified as in our previous study (Werner et al. 2008). We determined the initial error of each movement as the angular difference between cursor and target direction $150 \mathrm{~ms}$ after movement onset, i.e., before feedback-based corrections could become effective. The median value of this error for each episode and subject was used for subsequent analyses. Fur further data reduction, we calculated the adaptation indicators

adaptive improvement: $\mathrm{AI}\left({ }^{\circ}\right)=60-B+A$,

adaptive retention: $\operatorname{AR}\left({ }^{\circ}\right)=60-B+R$,

adaptive transfer: $\operatorname{AT}\left({ }^{\circ}\right)=60-B+T$,

de-adaptatation: $\mathrm{DA}\left(^{\circ}\right)=\mathrm{D}-\mathrm{B}$,

where $B$ and $A$ represent the mean initial error of the last three baseline and adaptation episodes, whereas $R, T$, and $D$ represent the initial error of the first retention, transfer and de-adaptation episode. No attempt was made to quantify the amount of savings by comparing the adaptation and retention phases.

As in our previous study (Werner et al. 2008), we quantified subjects' motor performance as the standard deviation of initial errors during the baseline phase (response variability, RV), the coefficient of determination between initial errors and the difference between initial and final errors during the adaptation phase (online correction ability, CA), as well as the mean movement time (MT), reaction time (RT), and peak velocity (PV) across the adaptation phase.

For statistical analysis, we submitted the initial errors of the adaptation phase to analyses of variance (ANOVAs) with the within-factor Episode and the between-factor Group (levels: control/PICA/SCA). To compensate for heterogeneity of variances, we applied Huynh-Feldt-corrections when necessary. In addition we submitted each adaptation indicator and motor performance parameter to a one-factor ANOVA with the between-factor Group. Significant effects of Group were explored with Fisher LSD post hoc tests.

Again as in our previous study (Werner et al. 2008), we examined the relationship between cerebellar disease, motor performance, and adaptive success by partitioning the variance of each adaptation indicator. To this end we first calculated several multiple linear correlations. $R_{\mathrm{P}}^{2}$ is 
the multiple coefficient of determination between adaptation indicator and motor performance measures, $R_{\mathrm{G}}^{2}$ is the simple coefficient of determination between adaptation indicator and Group (PICA/controls in a first step and SCA/ controls in a second step), and $R_{\mathrm{PG}}^{2}$ is the multiple coefficient of determination between adaptation indicator and Group as well as motor performance measures. With the help of those coefficients it is possible to calculate the variance that each adaptation indicator shares with motor performance measures $\left(\operatorname{Var}_{P}\right)$, with Group $\left(\operatorname{Var}_{G}\right)$, and with performance measures and Group jointly $\left(\mathrm{Var}_{\mathrm{J}}\right)$. These shared variances are given by

$\operatorname{Var}_{\mathrm{G}}=R_{\mathrm{PG}}^{2}-R_{\mathrm{P}}^{2}, \operatorname{Var}_{\mathrm{J}}=R_{\mathrm{G}}^{2}+R_{\mathrm{P}}^{2}-R_{\mathrm{PG}}^{2}$,

$\operatorname{Var}_{\mathrm{P}}=R_{\mathrm{PG}}^{2}-R_{\mathrm{G}}^{2}$,

For a more detailed explanation of this method, see, e.g., Bock and Girgenrath (2006).

Imaging data analysis

In the cerebellar patients, a 3D sagittal volume of the entire brain was acquired using a T1-weighted MPRAGE sequence $(\mathrm{FOV}=256 \mathrm{~mm}$, number of partitions $=160$, voxel size $=1.00 \times 1.00 \times 1.00 \mathrm{~mm}^{3}, \mathrm{TR} / \mathrm{TE}=2,400 /$ $4.38 \mathrm{~ms}$, flip angle $=8^{\circ}$ ) on a Siemens Sonata 1.5 T MR scanner. Ischemic lesions were manually traced on axial, sagittal and coronal slices of the non-normalized 3D-MRI data set and saved as region of interest (ROI) using MRIcro software (http://www.sph.sc.edu/comd/rorden/mricro.html ). Spatial normalization into standard proportional stereotaxic Montreal Neurological Institute (MNI) space was performed according to the masking technique described by Brett et al. (2001) using SPM2 (http://www.fil.ion.ucl. ac.uk/spm/; Wellcome Department of Cognitive Neurology, London, UK). Based on the MNI spatial coordinates of cerebellar lesions the corresponding cerebellar lobules were defined with the help of 3D-MRI atlases of the cerebellum (Schmahmann et al. 2000) and the cerebellar nuclei (Dimitrova et al. 2002). Lesions of vermis, paravermis and lateral hemispheres were considered separately (Schoch et al. 2004).

By performing a subtraction analysis (Karnath et al. 2002; Rorden et al. 2007) with the ROIs in MRICroN (http://www.sph.sc.edu/comd/rorden/mricron/), we were able to identify those cerebellar regions related to adaptation data (AI, AR, AT and DA). In a first step right-sided lesions were flipped to the left. Secondly, we assorted all patients into one subgroup with impaired AI, AR, AT or DA and one without impairment in AI, AR, AT or DA, respectively. The cut-off value for this classification was the mean value of all control subjects minus one standard deviation. The lesions for the impaired and unimpaired patients were added together, creating traditional overlap images showing the regions of mutual involvement. Thirdly we subtracted the overlap image of the unaffected patients from the impaired groups' overlap image. This was done for each adaptation variable separately. Our resulting images show regions which are commonly damaged in patients with affected AI, AR, AT or DA.

\section{Results}

Time course of adaptation

Figure 2 shows the mean initial error for each group and episode. During the baseline phase, initial errors were low for control subjects as well as for patients. At the beginning of adaptation phase, initial errors abruptly increased by a similar amount in all groups, and then gradually decrease again throughout the adaptation phase. This decrease was most pronounced and consistent in control subjects, less so in PICA patients, and least in SCA patients. These group differences persisted throughout the remaining experimental phases, except for the convergence of groups at the end of the de-adaptation phase. Initial de-adaptation errors
Fig. 2 Initial pointing error for all experimental episodes in SCA patients (black), PICA patients (grey), and controls (white). "Left" or "right" indicate episodes in which subjects used their left or right arm for pointing. Symbols represent across-subject means, and bars the pertinent standard deviations

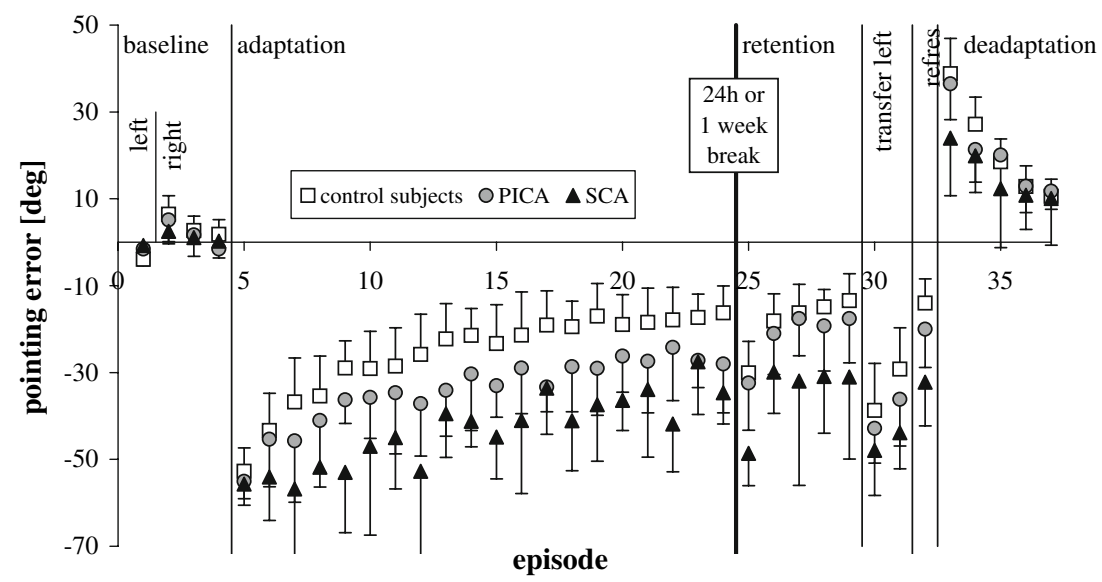


abruptly increase without returning to baseline level within five episodes, thus showing that at least some learning has taken place in all groups.

In accordance with these observations, ANOVA of the adaptation phase yielded significant effects of Group $(F(2,29)=18.38 ; p<0.001)$, Episode $(F(19,551)=9.50$; $p<0.001)$ and their interaction $(F(19,551)=18.99$; $p<0.05$ ), and post hoc decomposition revealed significant differences between control subjects and PICA $(p<0.01)$, control subjects and SCA $(p<0.001)$, as well as PICA and SCA $(p<0.05)$. For the retention and transfer phase, ANOVA yielded significant effects of Group $(F(2,29)=8.58 ; p<0.01$, and $F(2,29)=4.55 ; p<0.05$, respectively), and Episode $(F(4,116)=3.47 ; p<0.001$, and $F(1,29)=12.73 ; p<0.01$, respectively). Post hoc analysis showed significant differences between controls and SCA $(p<0.001)$, as well as PICA and SCA $(p<0.01)$ during the retention phase, but only between controls and SCA $(p<0.01)$ during the transfer phase. ANOVA for the de-adaptation phase yielded significant effects of Episode $(F(4,116)=3.37 ; \quad p<0.001)$ and Group $\times$ Episode $(F(4,116)=6.74 ; p<0.001)$, with significant difference between controls and SCA $(p<0.001)$, and PICA and SCA $(p<0.01)$ in the first episode. Furthermore, comparing the last baseline with the first de-adaptation episode reveals significant differences for all groups (controls $t(16)=15.009 ; \quad p=0.000, \quad$ PICA $\quad t(8)=10.573$; $p=0.000$ and SCA $t(5)=-4.149, p=0.009$ ), thus showing some aftereffect in all subjects.

To explore the role of lesion laterality, we submitted the initial errors of all experimental phases to an ANOVA with the within-factor Episode, and the between-factors Group (PICA/SCA) and Lesion Side (right/left). No significant effects including Lesion Side were yielded. Because all patients were tested with the right hand, one may expect that adaptation was less impaired in patients with left-sided cerebellar lesions compared to right-sided lesions. Ataxia score of the right upper limb, however, was not significantly different from the left upper limb in SCA $(t(5)=$ $-1.168 ; p=0.296)$ and PICA patients $(t(8)=-1.000$; $p=0.347)$.

Comparison of each adaptation indicator and motor performance parameter for PICA and SCA patients with either right or left sided lesions showed neither significant differences nor any trends. Note that our number of patients is small and a larger sample might lead to different results.

\section{Overall adaptation and performance scores}

One-way ANOVAs yielded significant effects of Group for the adaptation indicators $\mathrm{AI}(F(2,29)=12.12 ; p<0.001)$, $\operatorname{AR}(F(2,29)=9.73 ; p<0.001)$, and $\mathrm{DA}(F(2,29)=4.23$; $p<0.05)$, as well as for the performance parameters RT $(F(2,29)=3.85 ; \quad p<0.05)$, and $\mathrm{MT}(F(2,29)=7.14$; $p<0.001)$. The corresponding means are shown in Fig. 3, along with the outcome of post hoc analyses. For AT $(F(2,29)=0.95 ; \quad p=0.40), \quad$ CA $\quad(F(2,29)=1.07$; $p=0.36), \quad \operatorname{RV} \quad(F(2,29)=2.45 ; p=0.10), \quad$ and $\mathrm{PV}$ $(F(2,29)=1.66 ; p=0.21)$, the effect of Group did not reach statistical significance. For the performance measure $\mathrm{RV}$ we found an exceptionally large standard error in SCA patients as also shown in Fig. 3. The poorer adaptation as well as motor performance of the SCA group cannot be explained by a larger lesion size, since lesions were actually smaller in that group (SCA: $1.92 \pm 1.82 \mathrm{cc}$; PICA: $14.40 \pm 10.28 \mathrm{cc} ; t(13)=-2.91, p<0.5)$. Nor can it be explained by a larger ataxia, since ataxia scores did not differ between groups $(t(13)=-1.14, p>0.5)$.
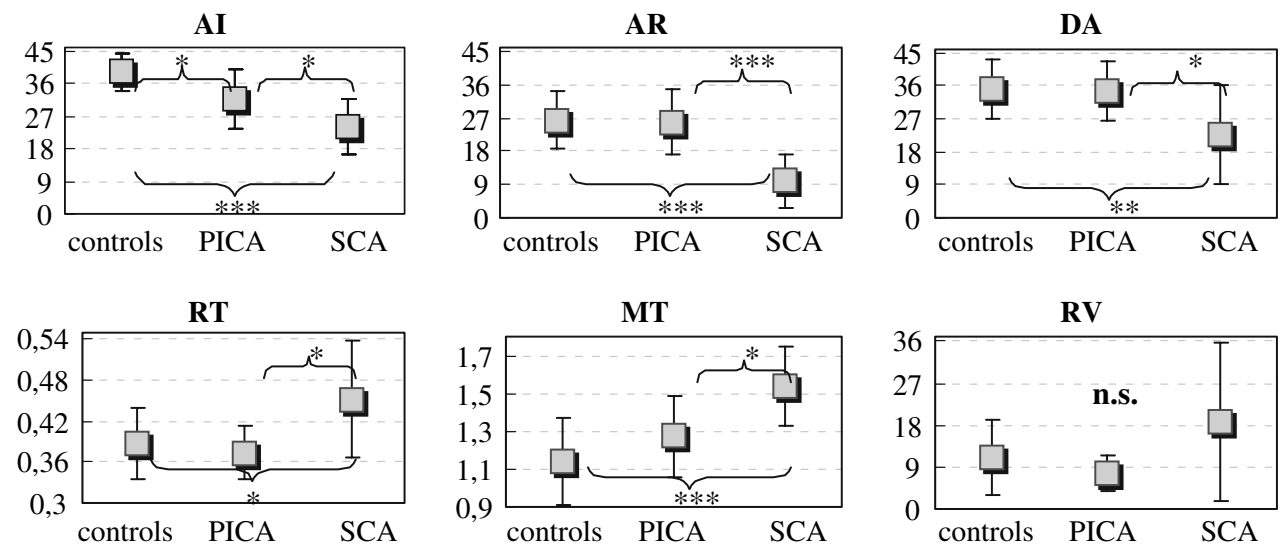

Fig. 3 Mean values and standard deviations for all three groups for $\mathrm{AI}, \mathrm{AR}, \mathrm{DA}, \mathrm{RT}, \mathrm{MT}$, and RV. The adaptation indicators were calculated by $\mathrm{AI}\left({ }^{\circ}\right)=60-B+A$, $\mathrm{AR}\left({ }^{\circ}\right)=60-B+R$, AT $\left(^{\circ}\right)=60-B+T$ and DA $\left(^{\circ}\right)=D-B$, where $B$ and $A$ represent the mean initial error of the last three baseline and adaptation episodes, whereas $R, T$, and $D$ represent the initial error of the first retention, transfer and de-adaptation episode. $* * *, * *, *$, and n.s. indicate $p<0.001, p<0.01, p<0.05$, and $p>0.05$, respectively. Note that the values of the $y$-axis stand for pointing errors in $\left(^{\circ}\right)(\mathrm{AI}, \mathrm{AR}, \mathrm{DA}$, $\mathrm{RV}$ ) or for time in s (RT, MT) 
Table 3 Results of multiple linear regression analyses for PICA/ controls and SCA/controls

\begin{tabular}{llll}
\hline (a) PICA & $\operatorname{Var}_{\mathrm{G}}$ & $\operatorname{Var}_{\mathrm{J}}$ & $\operatorname{Var}_{\mathrm{P}}$ \\
\hline AI & 0.096 & 0.146 & $0.366^{* * *}$ \\
AR & 0.001 & 0.000 & 0.150 \\
AT & 0.073 & -0.062 & $0.197^{*}$ \\
DA & 0.000 & 0.001 & $0.232^{*}$ \\
\hline (b) SCA & $\operatorname{Var}_{\mathrm{G}}$ & $\operatorname{Var}_{\mathrm{J}}$ & $\operatorname{Var}_{\mathrm{P}}$ \\
\hline AI & 0.049 & $0.523^{* * *}$ & $0.171^{*}$ \\
AR & 0.021 & $0.467^{* * *}$ & $0.197^{*}$ \\
AT & 0.015 & 0.059 & 0.137 \\
DA & 0.003 & $0.254^{*}$ & $0.283^{* *}$ \\
\hline
\end{tabular}

The total variance of each adaptation indicator was partitioned into a component $\operatorname{Var}_{\mathrm{G}}$ shared with subject group, but not with motor performance, a component $\operatorname{Var}_{\mathrm{J}}$ shared jointly with group and motor performance, and a component $\operatorname{Var}_{\mathrm{P}}$ shared with motor performance alone. Symbols ***, **, and * indicate $p<0.001, p<0.01$, and $p<0.05$, respectively, and the absence of a symbol indicates $p>0.05$

Finding an impairment in AI and DA for SCA patients and in AI but not DA for the PICA patients does not necessarily show, that the pattern is statistically significant for AI and DA measures. Therefore, we performed a further ANOVA with the within-factor Adaptation measure (AI, DA), and the between-factor Group. This analysis yielded a significant effect of Group $(F(2,29)=7.42$; $p<0.01)$ and a significant interaction Group $\times$ Adaptation measure $(F(2,29)=3.86 ; p<0.05)$. Post hoc analysis showed significant differences between PICA and controls $(p<0.05)$ as well as between SCA and controls $(p<0.001)$ for $\mathrm{AI}$, and between SCA and controls $(p<0.001)$ and between SCA and PICA $(p<0.01)$ but not between PICA and controls $(p>0.05)$ for DA.

One might argue that our results might be confounded by the fact that some of the patients show involvement of interposed (IN) and/or dentate nucleus (DN). However, replicating the one-way ANOVAs with the factor Group (controls/nucleus involvement/no nucleus involvement) or Group (control/DN involvement/no DN involvement) yielded no significant differences between those two patient groups.

\section{Partitioning of variances}

When control subjects and PICA patients are considered, the variance of our four adaptation indicators can be partitioned into the components shown in Table 3a. Thus, no indicator shares significant variance with Group only, nor with Group and motor parameters jointly, but three indicators share significant variance with motor parameters only. The corresponding analysis for control subjects and
SCA patients is found in Table 3b. Again, no indicator shares significant variance with Group only, but three share significant variance with Group and motor parameters jointly, as well as with motor parameters only.

To determine whether some motor parameters are more important than others, we replicated the analyses in Fig. 3, leaving out one motor parameter at a time. It was impossible to exclude any parameter without reducing the number of significant effects, which suggests that all parameters contribute to our results.

Localisation of adaptation and motor performance

Figure 4 shows the results of the ROI subtraction analyses for all adaptation variables. The percentage subtraction plots show areas that are more commonly damaged in patients with abnormal AI, AR, AT and DA compared to patients with those variables within the normal range based on control data. The lightest red represents $70 \%$ affected group and darkest blue designates regions where there is an identical percent of affected and unaffected groups $(0 \%)$. Cerebellar regions with the highest relative percentages of the number of ROIs in the impaired group were analysed based on MRI coordinates as outlined above.

Subtraction of the sum of the lesions of the subgroup with unimpaired AI from the patients with impaired AI revealed that affection of Crus I (green colour; MNI coordinates: $x=-18 \mathrm{~mm}, y=-82 \mathrm{~mm}, z=-36 \mathrm{~mm}$ and $x=-18 \mathrm{~mm}, y=-80 \mathrm{~mm}, z=-38 \mathrm{~mm}$ ) was $36 \%$ and lobule V (green colour; coordinates: $x=-20 \mathrm{~mm}$, $y=-46 \mathrm{~mm}, z=-20 \mathrm{~mm}$ ) was $27 \%$ more common in the AI-impaired subgroup (Schmahmann et al. 1999). For AR only affection of lobule $\mathrm{V}$ (green colour; coordinates: $x=-20 \mathrm{~mm}, y=-46 \mathrm{~mm}, z=-20 \mathrm{~mm}$ ) was $38 \%$ more common in impaired patients. Furthermore, for the transfer to the other hand Crus II bordering Crus I (yellow colour; coordinates: $x=-10$ to $-20 \mathrm{~mm}, y=-82$ to $-90 \mathrm{~mm}, z=-32$ to $-36 \mathrm{~mm}$ ) was $50 \%$ more commonly affected in the impaired subgroup and for DA lobule VI (yellow colour; coordinates: $x=-20 \mathrm{~mm}, y=-56 \mathrm{~mm}$, $z=-24 \mathrm{~mm}$ ) was $50 \%$ more commonly affected in DA-impaired patients.

\section{Discussion}

The purpose of the present study was to further elucidate the role of the cerebellum in visuomotor adaptation. We quantified several measures of motor performance as well as of visuomotor adaptation, and found that compared to healthy controls, patients with PICA territory lesions had deficits of adaptive improvement while their adaptive aftereffects and motor performance were not reliably 


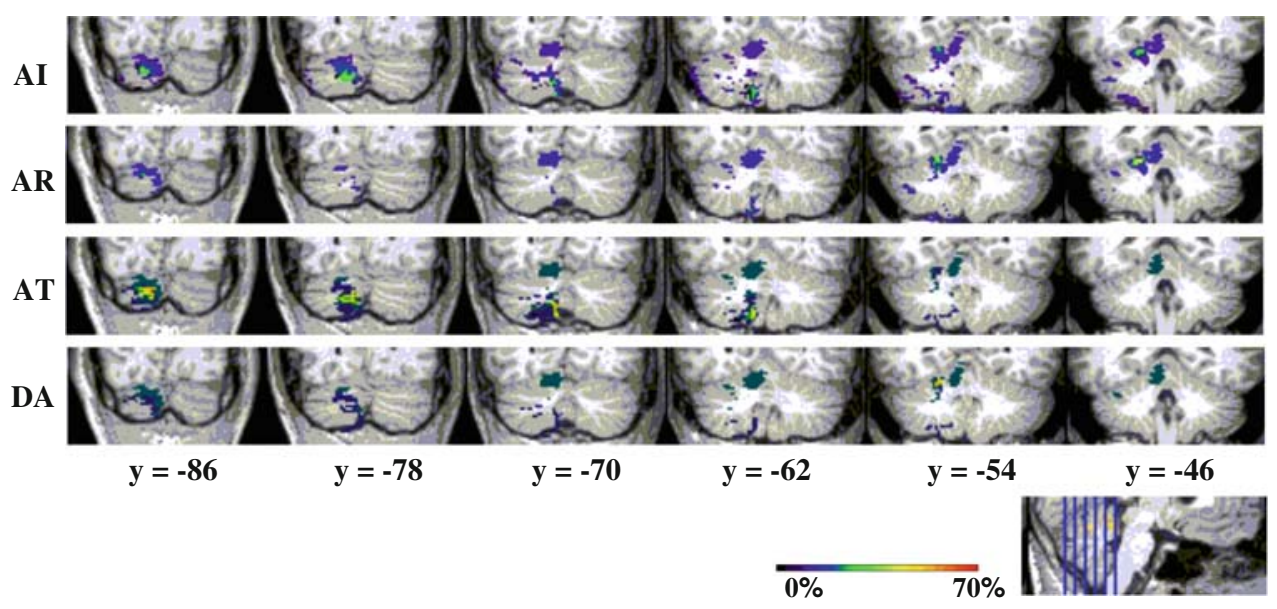

Fig. 4 MRI subtraction analysis comparing lesions in patients with impaired AI, AR, AT, or DA and unimpaired AI, AR, AT, or DA, respectively. The adaptation indicators were calculated by AI $\left(^{\circ}\right)=60-B+A, \operatorname{AR}\left(^{\circ}\right)=60-B+R$, AT $\left(^{\circ}\right)=60-B+T$ and DA $\left(^{\circ}\right)=D-B$, where $B$ and $A$ represent the mean initial error

degraded. Our aftereffect tests, adaptive retention and deadaptation, require newly developed sensory-to-motor transformation rules and thus indicate existing recalibration. Previous studies have shown a dissociation of adaptive improvement and aftereffect measures, for example dependent on age (Bock 2005) or on feedback source (Clower and Boussaoud 2000). Therefore, different underlying processes have been assumed. One might argue, that the de-adaptation measure must merely be the difference between the error of the last adaptation episode (with adaptation being achieved by strategic control or recalibration) minus the rotation magnitude $\left(60^{\circ}\right)$. This is true for the first de-adaptation movement. But already in the second movement, the subjects are cognitively aware of the change and must dismiss their previous strategy because it now becomes unsuccessful. Therefore, the first de-adaptation episode (about 15 movements) is dominated by recalibration (Clower and Boussaoud 2000; Bock 2005; McNay and Willingham 1998; Redding and Wallace 1996).

The pattern of our findings therefore suggests that adaptive recalibration remained largely intact in the PICA patients, while strategies like anticipations, associative stimulus-response pairings, and cognitive workaround schemes may be impaired. This would fit well with the observation that subjects with PICA territory lesions have problems on complex (Exner et al. 2004; Kalashnikova et al. 2005; Schmahmann and Sherman 1998) albeit not on simpler (Richter et al. 2007) cognitive tasks.

We further found that patients with SCA territory involvement had even more profound deficits of adaptive improvement, and were additionally impaired on adaptive aftereffects and motor performance. Also, we showed a of the last three baseline and adaptation episodes, whereas $R, T$, and $D$ represent the initial error of the first retention, transfer and deadaptation episode. Coronal views are shown $(-y=\mathrm{mm}$ behind anterior commissure). The colour indicates the level of percentage of a region to be more common lesioned in the impaired group

significant interaction for AI/DA $\times$ Group which confirms the assumption of a differentially impaired pattern for SCA and PICA patients. Following again the above line of reasoning, it appears that the SCA group in contrast to the PICA group indeed had deficits of adaptive recalibration. This finding fits well with a previous single-case study which also observed deficient adaptation effects and aftereffects in an SCA patient (Pisella et al. 2005), and with neuroimaging studies reporting adaptation-dependent neuronal activation in regions commonly supplied by the SCA but not the PICA territory. Furthermore, our findings are consistent with the results of a recent diffusion tensor imaging (DTI) study by Della-Maggiore et al. (2008). Here a positive correlation between the rate of adaptation and cerebellar white matter integrity was found in SCA regions. Also, our results are partly in line with the findings of Martin et al. (1996). Both studies agree that PICA patients show impaired adaptive improvement but intact motor performance. In our study, however, PICA patients were not impaired in measures of aftereffect, therefore, different to Martin et al. our results did not find impairment in true adaptation. Also, for SCA patients Martin et al. found normal adaptive improvement, deadaptation and motor performance in two subjects, and not measurable adaptation with substantial performance deficits in their third subject. At a more general level, the distinction between SCA- and PICA-related deficits in the present work is compatible with earlier research on other forms of motor learning: SCA but not PICA patients were found to be impaired on different types of eyeblink conditioning (Gerwig et al. 2003, 2005, 2006).

However, based on the present study alone, it cannot be directly differentiated between effects of strategic change 
and recalibration. The assumption of a differential contribution of the SCA and PICA territory to strategic change and recalibration needs to be confirmed in future experiments in cerebellar patients including clear manipulations (e.g. see Mazzoni and Krakauer 2006).

Unlike both previous studies with patients with focal lesions (Martin et al. 1996; Pisella et al. 2005), we found no lateralization of the adaptation deficit to the lesioned side. That is, in our study both lesions ipsi- and contralateral to the tested hand appeared to result in deficits in adaptive improvement and recalibration. This is in accordance to imaging data showing activation of bilateral anterior cerebellar regions correlated to the transfer between different angles of rotation (Seidler and Noll 2008), to error correction (Imamizu et al. 2000), and to motor execution (Grafton et al. 2008). In our study, however, no comparison of the lesioned and non-lesioned side was made. Also because of the small sample size, we cannot exclude that deficits are more pronounced on the ipsilesional compared to the contralesional side in a larger group of patients with focal lesions.

To further scrutinize the interrelation between adaptation and motor performance, we determined the variance shared between each adaptation indicator and group only $\left(\operatorname{Var}_{\mathrm{G}}\right)$, motor performance only $\left(\operatorname{Var}_{\mathrm{P}}\right)$, and group jointly with motor performance $\left(\operatorname{Var}_{\mathrm{J}}\right)$. Applying this approach to PICA patients and control subjects, we found that only $\operatorname{Var}_{\mathrm{P}}$, but not $\operatorname{Var}_{\mathrm{G}}$, was significant for most adaptation indicators, suggesting that regions outside of PICA territory are involved in motor performance which correlates with adaptive success. However, applying the same approach to SCA patients and controls revealed significant contributions of $\operatorname{Var}_{\mathrm{J}}$ in addition to $\operatorname{Var}_{\mathrm{P}}$ to the variances of adaptation variables. This can be interpreted as the involvement of SCA territory and extracerebellar brain regions in the monitoring and control of movements which correlates with adaptation. Confirming the outcome of our previous study (Werner et al. 2008), $\operatorname{Var}_{\mathrm{G}}$ did not reach statistical significance in either data set, i.e., we found again no evidence for a cerebellar contribution to adaptation but not to motor performance. This, however, does not say that adaptation disorders are caused by motor performance deficits. Likewise, similar disorders may lead to both disordered adaptation and motor performance abnormalities, or, adaptation deficits may lead to motor performance deficits.

A subtraction analysis of MRI lesion data revealed that regions of the posterior lobe (Crus I) as well as regions of the anterior lobe (lobule $\mathrm{V}$ ) show common overlap for disordered adaptive improvement. Crus I is commonly supplied by the SCA. However, variation exists and PICA territory can involve Crus I. In fact, in our study, in 7 of 9 PICA patients Crus I was affected, but only in 2 of 6 SCA patients. For visuomotor recalibration, however, lobules $\mathrm{V}$ (anterior lobe) and VI (most superior part of the posterior lobe) were the most crucial lesion sites. In line with the results of our subtraction analysis only 3 of 9 PICA patients with Crus I involvement were impaired in AR and 2 of 9 patients in DA. This region of the superior cerebellum has been discussed in numerous imaging studies as important for the processing of performance errors (Diedrichsen et al. 2005; Grafton et al. 2008), for the transfer of adaptation (Seidler and Noll 2008), and as a storage site for internal models (Imamizu et al. 2000). A recent lesion study tested visuomotor adaptation in patients with cerebellar degeneration (Rabe et al. 2009) and found a significant negative correlation between the adaptation deficits and the degree of cerebellar atrophy in the intermediate zone of the posterior lobe. Since their adaptation measure includes aiming errors during adaptation phase as well as catch trials, it can be compared to both our AI and DA. For those variables we find an involvement of the more intermediate parts of lobules Crus I and VI (which are parts of the cerebellar posterior lobe) and are in accordance with the results in degenerative patients. For the transfer to the other hand subtraction analysis reveals an involvement of a more posterior region (Crus II bordering Crus I). This result indicates that the intermanual transfer might not indicate a deficit in recalibration in cerebellar patients but does require strategic control. Finally, our results cannot be explained by a difference in lesion size in the two patient groups. On the contrary, mean lesion size of our PICA patients was significantly larger than that of our SCA patients. This shows that the exact location of the lesion is more essential than mere size.

The present study as well as previous human cerebellar lesion studies (Deuschl et al. 1996; Gauthier et al. 1979; Maschke et al. 2004; Morton and Bastian 2004; Smith and Shadmehr 2005; Synofzik et al. 2008; Tseng et al. 2007; Weiner et al. 1983; Werner et al. 2008) examined adaptation to sudden visuomotor perturbations. Animal cerebellar lesion studies suggest that abnormalities may be more marked following adaptation to gradual perturbations (Robertson and Miall 1999). It would be of interest to compare adaptation to gradual and sudden perturbation in future studies in cerebellar patients.

In conclusion, the present study confirms the importance of the cerebellum for visuomotor adaptation. While adaptive improvement was impaired in both PICA and SCA patient groups visuomotor recalibration seems to be located within the SCA territory especially lobules V and VI being of particular importance.

Acknowledgments This work was supported by DFG Grant Bo 649/8 awarded to O.B. Responsibility for contents rests with the authors. Thanks go to Lutz Geisen for software development, and Beate Brol, Maike Böttger, Karin Hengherr and Christina Geissler who assisted with data collection and processing. 
Open Access This article is distributed under the terms of the Creative Commons Attribution Noncommercial License which permits any noncommercial use, distribution, and reproduction in any medium, provided the original author(s) and source are credited.

\section{References}

Bock O (2005) Components of sensorimotor adaptation in young and elderly subjects. Exp Brain Res 160:259-263

Bock O, Girgenrath M (2006) Relationship between sensorimotor adaptation and cognitive functions in younger and older subjects. Exp Brain Res 169:400-406

Brett M, Leff AP, Rorden C, Ashburner J (2001) Spatial normalization of brain images with focal lesions using cost function masking. Neuroimage 14:486-500

Chase C, Seidler R (2008) Degree of handedness affects intermanual transfer of skill learning. Exp Brain Res 190:317-328

Clower DM, Boussaoud D (2000) Selective use of perceptual recalibration versus visuomotor skill acquisition. J Neurophysiol 84:2703-2708

Della-Maggiore V, McIntosh AR (2005) Time course of changes in brain activity and functional connectivity associated with longterm adaptation to a rotational transformation. $\mathrm{J}$ Neurophysiol 93:2254-2262

Della-Maggiore V, Johansen-Berg H, Paus T (2008) The rate of visuomotor adaptation is associated with white matter integrity of cerebellar projections to motor cortices. In: Neuroscience 2008. Washington DC, USA

Deuschl G, Toro C, Zeffiro T, Massaquoi S, Hallett M (1996) Adaptation motor learning of arm movements in patients with cerebellar disease. J Neurol Neurosurg Psychiatry 60:515-519

Diedrichsen J, Hashambhoy Y, Rane T, Shadmehr R (2005) Neural correlates of reach errors. J Neurosci 25:9919-9931

Dimitrova A, Weber J, Redies C, Kindsvater K, Maschke M, Kolb FP, Forsting M, Diener HC, Timmann D (2002) MRI atlas of the human cerebellar nuclei. Neuroimage 17:240-255

Exner C, Weniger G, Irle E (2004) Cerebellar lesions in the PICA but not SCA territory impair cognition. Neurology 63:2132-2135

Gauthier GM, Hofferer JM, Hoyt WF, Stark L (1979) Visual-motor adaptation. Quantitative demonstration in patients with posterior fossa involvement. Arch Neurol 36:155-160

Gerwig M, Dimitrova A, Kolb FP, Maschke M, Brol B, Kunnel A, Boring D, Thilmann AF, Forsting M, Diener HC, Timmann D (2003) Comparison of eyeblink conditioning in patients with superior and posterior inferior cerebellar lesions. Brain 126:71-94

Gerwig M, Hajjar K, Dimitrova A, Maschke M, Kolb FP, Frings M, Thilmann AF, Forsting M, Diener HC, Timmann D (2005) Timing of conditioned eyeblink responses is impaired in cerebellar patients. J Neurosci 25:3919-3931

Gerwig M, Haerter K, Hajjar K, Dimitrova A, Maschke M, Kolb FP, Thilmann AF, Gizewski ER, Timmann D (2006) Trace eyeblink conditioning in human subjects with cerebellar lesions. Exp Brain Res 170:7-21

Grafton ST, Schmitt P, Van Horn J, Diedrichsen J (2008) Neural substrates of visuomotor learning based on improved feedback control and prediction. Neuroimage 39:1383-1395

Imamizu H, Miyauchi S, Tamada T, Sasaki Y, Takino R, Putz B, Yoshioka T, Kawato M (2000) Human cerebellar activity reflecting an acquired internal model of a new tool. Nature 403:192-195

Imamizu H, Kuroda T, Miyauchi S, Yoshioka T, Kawato M (2003) Modular organization of internal models of tools in the human cerebellum. Proc Natl Acad Sci USA 100:5461-5466
Kalashnikova LA, Zueva YV, Pugacheva OV, Korsakova NK (2005) Cognitive impairments in cerebellar infarcts. Neurosci Behav Physiol 35:773-779

Karnath HO, Himmelbach M, Rorden C (2002) The subcortical anatomy of human spatial neglect: putamen, caudate nucleus and pulvinar. Brain 125:350-360

Martin TA, Keating JG, Goodkin HP, Bastian AJ, Thach WT (1996) Throwing while looking through prisms. I. Focal olivocerebellar lesions impair adaptation. Brain 119(Pt 4):1183-1198

Maschke M, Gomez CM, Ebner TJ, Konczak J (2004) Hereditary cerebellar ataxia progressively impairs force adaptation during goal-directed arm movements. J Neurophysiol 91:230-238

Mazzoni P, Krakauer JW (2006) An implicit plan overrides an explicit strategy during visuomotor adaptation. J Neurosci 26:3642-3645

McNay EC, Willingham DB (1998) Deficit in learning of a motor skill requiring strategy, but not of perceptualmotor recalibration, with aging. Learn Mem 4:411-420

Morton SM, Bastian AJ (2004) Prism adaptation during walking generalizes to reaching and requires the cerebellum. J Neurophysiol 92:2497-2509

Nezafat R, Shadmehr R, Holcomb HH (2001) Long-term adaptation to dynamics of reaching movements: a PET study. Exp Brain Res 140:66-76

Pisella L, Rossetti Y, Michel C, Rode G, Boisson D, Pelisson D, Tilikete $C$ (2005) Ipsidirectional impairment of prism adaptation after unilateral lesion of anterior cerebellum. Neurology 65:150 152

Rabe K, Livne O, Gizewski ER, Aurich V, Beck A, Timmann D, Donchin O (2009) Adaptation to visuomotor rotation and force field perturbation is correlated to different brain areas in patients with cerebellar degeneration. J Neurophysiol 101:1961-1971

Redding GM, Wallace B (1996) Adaptive spatial alignment and strategic perceptual-motor control. J Exp Psychol Hum Percept Perform 22:379-394

Redding GM, Rossetti Y, Wallace B (2005) Applications of prism adaptation: a tutorial in theory and method. Neurosci Biobehav Rev 29:431-444

Richter S, Aslan B, Gerwig M, Wilhelm H, Kramer S, Todica O, Schoch B, Dimitrova A, Gizewski ER, Thilmann AF, Timmann D (2007) Patients with chronic focal cerebellar lesions show no cognitive abnormalities in a bedside test. Neurocase 13:25-36

Robertson EM, Miall RC (1999) Visuomotor adaptation during inactivation of the dentate nucleus. Neuroreport 10:1029-1034

Rorden C, Karnath HO, Bonilha L (2007) Improving lesion-symptom mapping. J Cogn Neurosci 19:1081-1088

Schmahmann JD, Sherman JC (1998) The cerebellar cognitive affective syndrome. Brain 121(Pt 4):561-579

Schmahmann JD, Doyon J, McDonald D, Holmes C, Lavoie K, Hurwitz AS, Kabani N, Toga A, Evans A, Petrides M (1999) Three-dimensional MRI atlas of the human cerebellum in proportional stereotaxic space. Neuroimage 10:233-260

Schmahmann JD, Doyon J, Toga A, Petrides M, Evans A (2000) MRI Atlas of the human cerebellum. Academic Press, San Diego

Schmitz-Hubsch T, du Montcel ST, Baliko L, Berciano J, Boesch S, Depondt C, Giunti P, Globas C, Infante J, Kang JS, Kremer B, Mariotti C, Melegh B, Pandolfo M, Rakowicz M, Ribai P, Rola R, Schols L, Szymanski S, van de Warrenburg BP, Durr A, Klockgether T, Fancellu R (2006) Scale for the assessment and rating of ataxia: development of a new clinical scale. Neurology 66:1717-1720

Schoch B, Gorissen B, Richter S, Ozimek A, Kaiser O, Dimitrova A, Regel JP, Wieland R, Hovel M, Gizewski E, Timmann D (2004) Do children with focal cerebellar lesions show deficits in shifting attention? J Neurophysiol 92:1856-1866 
Seidler RD, Noll DC (2008) Neuroanatomical correlates of motor acquisition and motor transfer. J Neurophysiol 99:1836-1845

Seidler RD, Noll DC, Thiers G (2004) Feedforward and feedback processes in motor control. Neuroimage 22:1775-1783

Seidler RD, Noll DC, Chintalapati P (2006) Bilateral basal ganglia activation associated with sensorimotor adaptation. Exp Brain Res 175:544-555

Shadmehr R, Holcomb HH (1997) Neural correlates of motor memory consolidation. Science 277:821-825

Smith MA, Shadmehr R (2005) Intact ability to learn internal models of arm dynamics in Huntington's disease but not cerebellar degeneration. J Neurophysiol 93:2809-2821

Synofzik M, Lindner A, Thier P (2008) The cerebellum updates predictions about the visual consequences of one's behavior. Curr Biol 18:814-818
Timmann D, Konczak J, Ilg W, Donchin O, Hermsdörfer J, Gizewski E, Schoch B (2009) Current advances in lesion-symptom mapping of the human cerebellum. Neuroscience 162:836-851

Tseng YW, Diedrichsen J, Krakauer JW, Shadmehr R, Bastian AJ (2007) Sensory prediction errors drive cerebellum-dependent adaptation of reaching. J Neurophysiol 98:54-62

Weiner MJ, Hallett M, Funkenstein HH (1983) Adaptation to lateral displacement of vision in patients with lesions of the central nervous system. Neurology 33:766-772

Werner S, Bock O (2007) Effects of variable practice and declarative knowledge on sensorimotor adaptation to rotated visual feedback. Exp Brain Res 178:554-559

Werner S, Bock O, Timmann D (2008) The effect of cerebellar cortical degeneration on adaptive plasticity and movement control. Exp Brain Res 193:189-196 